\title{
Estado oxidativo de cuerpos lúteos maduros y regresivos en bovinos
}

\author{
Márquez, Y.C. ${ }^{1}$; Márquez, A. ${ }^{1}$; Fuentes, M. ${ }^{3}$; Salas, Y. ${ }^{2}$; López-Ortega, A. ${ }^{1}$ \\ ${ }^{1}$ UNHIM, ${ }^{2}$ Área de Patología Animal y ${ }^{3}$ Área de Investigación, Facultad de Ciencias Veterinarias, Universidad \\ Centroccidental "Lisandro Alvarado" (UCLA), Barquisimeto (Lara, Venezuela). Tel. 0251-2592630. \\ Email: isabelmarquez@ucla.edu.ve.
}

\begin{abstract}
Resumen
Márquez, Y.C.; Márquez, A.; Fuentes, M.; Salas, Y.; López-Ortega, A.: Estado oxidativo de cuerpos lúteos maduros y regresivos en bovinos. Rev. vet. 22: 1, 25-31, 2011. El objetivo del trabajo fue determinar en diferentes períodos evolutivos el estado oxidativo de los cuerpos lúteos (CL) de bovinos, mediante la concentración de malondialdehído (MDA), dienos conjugados (DC), actividad de superóxido dismutasa (SOD) y su presencia por inmunofluorescencia indirecta (IFI). Para determinar MDA y DC se homogenizaron $30 \mathrm{CL}$ en buffer tris-sacarosa $250 \mathrm{mM} \mathrm{pH} \mathrm{7,2} \mathrm{a} 4^{\circ} \mathrm{C}$. En el sobrenadante se determinó MDA por "sustancias reactivas al ácido tiobarbitúrico" (TBARS) y DC mediante extracción con isopropanol. Para SOD 26 CL fueron homogenizados en sacarosa $0,25 \mathrm{M}$ en una relación de 10 $\mathrm{ml} / \mathrm{g}$ de tejido húmedo según kit Calbiochem. En el caso de la de la IFI de CuZn-superóxido dismutasa se realizaron cortes de $133 \mathrm{CL}$. Los resultados de MDA, DC y SOD se analizaron estadísticamente por el test "t" con una significancia del 5\% y para IFI se aplicó estadística descriptiva. Los CL maduros dieron valores de 25,94 $\pm 2,68$ nmoles MDA/mg proteína (437,96 $\pm 56,61 / \mathrm{g}$ de tejido húmedo) y el CL en regresión de $6,65 \pm 0,87(143,04 \pm 15,45)(\mathrm{p}<0,001)$. En los DC se obtuvieron valores de $14,76 \pm 2,60 \mathrm{nmoles} / \mathrm{mg}$ proteínas $(294,86 \pm 57,96 / \mathrm{g}$ tejido húmedo) para los CL maduros y de 6,66 $\pm 1,76$ nmoles/mg proteínas $(129,10 \pm 9,8 / \mathrm{g}$ tejido húmedo) para los CL regresivos ( $\mathrm{p}<0,001)$. La actividad SOD en CL maduros alcanzó valores de $119,01 \pm 42,38 \mathrm{U} / \mathrm{mg}$ proteína, para declinar en forma altamente significativa en los CL en regresión $(26,28 \pm 4,38)$. En el total de CL maduros y en regresión, se evidenció la presencia por IFI, cuyo grado de fluorescencia resultó alto en el $71,25 \%$ de los CL maduros y leve en el 71,69\% de los regresivos, con una correlación de 33\% entre los dos estadios del CL y la presencia de la enzima $(p \leq 0,05)$. Se concluye que en los CL maduros existe equilibrio entre producción de radicales libres y estado antioxidante, al compararlos con los CL en estado de regresión.
\end{abstract}

Palabras clave: bovino, cuerpo lúteo, estrés oxidativo.

\begin{abstract}
Márquez, Y.C.; Márquez, A.; Fuentes, M.; Salas, Y.; López-Ortega, A.: Oxidative status of mature and regressive corpus luteum in cattle. Rev. vet. 22: 1, 25-31, 2011. The objectives of the present study were: (1) to measure the amount of malondialdehyde (MDA) and conjugated dienes (CD); (2) to determine the antioxidative capacity of the superoxide dismutase enzyme (SOD); and (3) to detect the presence of SOD in mature and regressive corpus luteum (CL) in cattle. Measurement of MDA and CD were performed in $30 \mathrm{CL}$ homogenized in tris-saccharose buffer $\left(250 \mathrm{mM} \mathrm{pH} \mathrm{7.2)}\right.$ at $4^{\circ} \mathrm{C}$ to obtain the supernatant. TBARS method was used to determine MDA and isopropanol extraction to analyze $\mathrm{CD}$. Calbiochem kit was used to quantify SOD activity from $26 \mathrm{CL}$. Indirect immunefluorescence (IFI) was used to detect $\mathrm{CuZn}-\mathrm{SOD}$ presence from $133 \mathrm{CL}$ slides. Statistical differences were determine by the $\mathrm{t}$-test $(\mathrm{p}<0.05)$ and IFI results were described based on frequency of immunefluorescence (high, medium, and low). Means of MDA were $25.94 \pm 2.68$ and $6.65 \pm 0.87 \mathrm{MDA} / \mathrm{mg}$ of protein in mature and regressive $C L$, respectively $(\mathrm{p}<0.001)$. Means of $C D$ were $14.76 \pm 2.60 \mathrm{x}$ $10^{-3}$ and $6.66 \pm 1.76 \times 10^{-3} \mathrm{nmol} / \mathrm{mg}$ protein in mature and regressive $\mathrm{CL}$, respectively $(\mathrm{p}<0.05)$. Activity of the $\mathrm{CuZn}-\mathrm{SOD}$ in mature $\mathrm{CL}$ reached values of $119.01 \pm 42.38 \mathrm{U} / \mathrm{mg}$ protein but decline sharply in regressive CL reaching $26.28 \pm 4.38(\mathrm{p}<0.001)$. The presence of the enzyme $\mathrm{CuZn}-\mathrm{SOD}$ was demonstrated in all CL analyzed. However, $71.25 \%$ of mature CL presented high fluorescence as compared to regressive $\mathrm{CL}$, while the majority of regressive $\mathrm{CL}$ (71.69\%) presented low fluorescence. In conclusion, mature CL had a higher activity of SOD
\end{abstract}

Recibido: 11 febrero 2011 / Aceptado: 24 mayo 2011 


\begin{abstract}
than regressive CL for the present study. These results suggest that mature bovine CL had an increased production of ROS together with an increased antioxidative activity as compared to regressive CL. Possibly this increment could be due to the high steroidogenic capacity of CL during mature stage. Thus, the increase in the antioxidative capacity of the luteal cells prevents the oxidative stress even though there is an increase of ROS assuring that CL could complete its physiological cycle.
\end{abstract}

Key words: cattle, corpus luteum, oxidative stress.

\section{INTRODUCCIÓN}

Los radicales libres (RL), entre ellos las formas reactivas del oxígeno (ROS) se generan constantemente en el organismo, en muchos casos para cumplir funciones fisiológicas; no obstante cuando se producen en exceso pueden provocar estrés oxidativo, especialmente ante la presencia de iones como hierro $\left(\mathrm{Fe}^{+3}\right)$ o cobre $\left(\mathrm{Cu}^{+2}\right)$. El exceso de ROS puede producir daño a lípidos de las membranas celulares o lipoperoxidación de proteínas, carbohidratos y $\mathrm{ADN}^{4,11}$.

Así como los RL se forman durante el proceso oxidativo normal, en el organismo se sintetizan enzimas capaces de metabolizarlos, las cuales interrumpen la reacción de peroxidación de la cadena lipídica por poseer hidrogeniones fácilmente donables, lo cual provoca abstracción de los radicales peróxidos ${ }^{15}$. Entre las enzimas antioxidantes se encuentran: superóxido dismutasa (SOD), catalasa, glutatión-S-transferasa y glutatión peroxidasa (GPx) entre otras ${ }^{6}$. Existen también otros compuestos capaces de neutralizar la acción de los radicales libres debido a su carácter antioxidante, como las vitaminas E, A, beta-caroteno y glutatión ${ }^{11}$.

La muerte embrionaria temprana en las vacas es uno de los mayores problemas reproductivos de la ganadería. Puede ser provocada por gran cantidad de factores, entre los cuales resalta la luteólisis temprana en hembras preñadas, que provoca disminución de la concentración de progesterona $\left(\mathrm{P}_{4}\right)$ e interrupción de la preñez puesto que la producción inicial de $\mathrm{P}_{4}$ viene dada por el cuerpo lúteo (CL).

El CL es una glándula endocrina transitoria que produce $\mathrm{P}_{4}$ durante un tiempo determinado. En ausencia de preñez el CL sufre un proceso de regresión conocido como luteólisis, la cual se divide en funcional, por pérdida de la capacidad de sintetizar $\mathrm{P}_{4}$ y estructural, por pérdida de integridad celular ${ }^{5}$. La luteólisis es inducida principalmente por prostaglandina $\mathrm{F}_{2} \alpha$ $\left(\mathrm{PGF}_{2} \alpha\right)$ y de manera secundaria a través de otras rutas paralelas mediadas por calcio, citoquinas, ROS y endotelinas. Todos estos factores conducen finalmente a la inhibición de la esteroidogénesis y/o inducción de la apoptosis ${ }^{17}$.

Durante la síntesis de $\mathrm{P}_{4}$, el colesterol es transportado a la mitocondria para convertirse en pregnenolona. Los ROS formados en esta reacción causan peroxidación lipídica en la mitocondria, pudiendo inhibir de esta manera la actividad del sistema enzimático mitocondrial y al mismo tiempo servir como reguladores de la síntesis de pregnenolona. Un radical libre muy tóxico, el anión superóxido $\left(\mathrm{O}_{2}^{-}\right)$, es transformado en las células luteales a peróxido de hidrógeno $\left(\mathrm{H}_{2} \mathrm{O}_{2}\right)$, molécula luteolítica que produce inhibición del transporte de colesterol a la mitocondria, con la subsiguiente disminución de la síntesis de $\mathrm{P}_{4}{ }^{14} \mathrm{y}$ fallas en el funcionamiento normal del CL, incluyendo la luteólisis prematura, que resulta en muerte embrionaria o abortos espontáneos, lo cual se evidencia por la presencia de vacas repetidoras de celo con el consiguiente efecto negativo sobre la fertilidad del rebaño.

El objetivo de este trabajo fue determinar el estado oxidativo de CL bovinos en diferentes períodos evolutivos, mediante la concentración de malondialdehído (MDA) dienos conjugados (DC), actividad de CuZnsuperóxido dismutasa (CuZn-SOD) y presencia de esta enzima por inmunofluorescencia.

\section{MATERIAL Y MÉTODOS}

\section{Parámetros de estrés oxidativo}

a. Sujetos experimentales, muestras. Se utilizaron 31 hembras bovinas mestizas adultas no preñadas con buena condición corporal, las cuales se obtuvieron en el Matadero Industrial de Barquisimeto (Estado de Lara, Venezuela). A todos los animales se les determinó la presencia de CL por palpación rectal. Los ovarios fueron separados e inmediatamente colocados en buffer tris-sacarosa $250 \mathrm{mM} \mathrm{pH} \mathrm{7,2} \mathrm{a} 4^{\circ} \mathrm{C}$ (hielo), para ser transportados al laboratorio. Cada CL fue pesado, medido su diámetro y registrado su aspecto macroscópico. De acuerdo a estas características se separaron en dos grupos según estadio: maduros y en regresión.

b. Determinación de MDA y DC. Muestras de CL de cada estadio fueron colocadas en buffer tris-sacarosa $250 \mathrm{mM} \mathrm{pH} \mathrm{7,2} \mathrm{a} 4^{\circ} \mathrm{C}$ y tratadas en un homogeneizador de émbolo y tubo (Potter-Elvehjem). En el sobrenadante se determinó la concentración de MDA por el método de "sustancias reactivas al ácido tiobarbitúrico" (TBARS) ${ }^{16}$ y los DC por extracción con isopropanol ${ }^{18}$, ${ }^{24}$. Los resultados se expresaron en $\mathrm{nmol} / \mathrm{mg}$ de proteína y por g de tejido húmedo.

c. Concentración de proteínas totales. En $20 \mu \mathrm{l}$ del sobrenadante de los homogenizados de cuerpo lúteo se determinaron las proteínas totales mediante kit Bio Rad (Richmond, CA, USA), utilizando como standard 
diluciones de una solución de $1,41 \mathrm{mg} / \mathrm{ml}$ de albúmina sérica bovina. Las lecturas se realizaron a una longitud de onda de $540 \mathrm{~nm}$ en un espectrofotómetro Spectronic Genesys 5.

\section{Respuesta antioxidante luteal}

a. Actividad SOD. Para la determinación de SOD se homogenizó la muestra con una solución de sacarosa $0,25 \mathrm{M}$ en una relación de $10 \mathrm{ml} / \mathrm{g}$ de tejido y se mantuvo durante todo el proceso a $4^{\circ} \mathrm{C}$. Posteriormente se centrifugó a $12.000 \mathrm{rpm}$ por 10 minutos a $4^{\circ} \mathrm{C}$, se colectó el sobrenadante y se procedió según kit Calbiochem (Lajilla, CA, USA). Las mediciones se realizaron en un espectrofotómetro Spectronic Genesys 5 a una absorbancia $525 \mathrm{~nm}$ a intervalos de 10 segundos durante 3 minutos.

b. Identificación de $\mathrm{Cu}-\mathrm{Zn}$-superóxido dismutasa. Se realizó por inmunofluorescencia indirecta. Los cortes sobre la lámina portaobjeto se desparafinaron y se incubaron con el anticuerpo primario anti SOD-Cu-Zn goat polyclonal $\lg G$ (C-17 Santa Cruz Biotechnology) diluido en solución de buffer fosfatada (PBS) 1:200 (dilución previamente estandarizada), y se dejó reposar durante una hora a temperatura ambiente. Seguidamente, protegido de la luz y a temperatura ambiente se procedió a incubar con el anticuerpo secundario anti goat IgG FITC conjugate (Catálogo 075-10 VMRD Inc.) conjugado con isotiocianato de fluoresceína y diluido 1:50 con PBS. La muestra utilizada como control negativo no fue incubada con el anticuerpo primario. Finalmente, a cada muestra se le agregó el medio de montaje para fluorescencia y se protegió con cubreobjetos para ser observada en el microscopio de fluorescencia (Lieder ME-600).

\section{Análisis estadístico}

Los datos obtenidos en las determinaciones de parámetros de estrés oxidativo y actividad enzimática se sometieron a estudio estadístico mediante el test de " $\mathrm{t}$ " de Student. Las diferencias de las medias fueron consideradas significativas para una $p<0,05$. Para analizar los resultados de la presencia de actividad CuZn-SOD en CL, se realizó estadística descriptiva (media aritmética y desvío estándar, $\mathrm{X} \pm \mathrm{DE}$ ), en todos los casos empleando el paquete estadístico SPSS 10.0 para Windows.

\section{RESULTADOS Y DISCUSION}

\section{Cuantificación de la lipoperoxidación}

En la Tabla 1 se muestra la concentración de MDA y DC en homogenizados de CL bovinos en estadios de madurez y regresión. La concentración de MDA, producto final del proceso de lipoperoxidación (LPO), fue cuatro veces mayor en los $C L$ maduros $(p<0,001)$.
Tabla 1. Concentración de MDA y DC en CL maduros y regresivos.

\begin{tabular}{lcc}
\hline estadio del CL & MDA & DC \\
\hline maduro & $24,94 \pm 2,68^{\mathrm{a}}$ & $14,70 \pm 2,60^{\mathrm{a}}$ \\
en regresión & $6,65 \pm 0,87^{\mathrm{b}}$ & $6,66 \pm 1,70^{\mathrm{b}}$ \\
\hline
\end{tabular}

CL: cuerpo lúteo, MDA: malondialdehído (nmol/mg proteína), DC: dienos conjugados ( $\mathrm{mol} / \mathrm{mg}$ proteína $10^{-5}$ ). Los valores representan $\mathrm{X} \pm \mathrm{DS}$. Letras distintas en la misma columna indican diferencias significativas.

También en éstos la concentración de DC (productos iníciales de la LPO) se presentó dos veces mayor a la obtenida en los CL en regresión, con una diferencia significativa entre los dos grupos $(p<0,05)$. Todo ello indica que el proceso de LPO se lleva a cabo en el estadio de madurez, sentando las bases para el inicio de la luteólisis.

Tales hallazgos son concordantes con los reportados por otros autores ${ }^{23}$ quienes verificaron que en la mujer, la máxima capacidad esteroidogénica del CL se manifiesta en el estadio intermedio de la fase luteal (CL maduro), en coincidencia con bajos niveles de glutatión reducido, el cual es un agente antioxidante, altos valores de MDA y elevada actividad de SOD, que degrada al radical superóxido. En los CL en regresión se observó una drástica disminución de la actividad pro-oxidante, evidenciada por la disminución de los valores de MDA y DC, mientras que en el CL maduro se observó un aumento de estos parámetros y en consecuencia un efecto de LPO de las membranas lipídicas. Estos hechos concuerdan con la aumentada actividad de SOD observada en este trabajo en el CL maduro y con la presencia de la enzima en este estadio evolutivo.

Queda demostrado que hay una notable actividad pro-oxidante en las células luteales maduras al mismo tiempo que existe aún alta capacidad antioxidante, lo que permite que este órgano endocrino temporal siga ejerciendo su función sin que ocurra una degeneración luteal prematura. Una vez que llega al máximo de producción debe existir un agotamiento de la actividad enzimática, lo que podría dar inicio a un estado de estrés oxidativo ${ }^{7}$. Este estado traería como consecuencia el proceso de lipoperoxidación de las membranas celulares, lo que contribuiría al inicio de la luteólisis.

\section{Respuesta antioxidante luteal}

\section{a. Actividad de SOD}

Teniendo en cuenta que la actividad SOD en la fase inicial fue de 1,573 $\pm 0,54 \mathrm{U} / \mathrm{ml}$, la Figura 1 indica que en CL maduros alcanzó valores de 4,002 $\pm 0,596 \mathrm{U} / \mathrm{ml}$ (incremento de $60,68 \%$ ), para declinar un $70,83 \%$ en la fase de regresión con una media de 1,167 U/ml.

En ovejas se registró un desbalance en los agentes pro-oxidantes/antioxidantes durante la preñez, debido al estrés que implica este estadio fisiológico ${ }^{10}$. Los resultados aquí obtenidos para la actividad SOD en las 
distintas etapas del CL, se asemejan a los reportados por otros autores, quienes indican que la enzima disminuye en el cuerpo lúteo humano en regresión con respecto a la fase de madurez ${ }^{2,23}$.

En la fase luteolítica, el balance de la actividad de las enzimas luteolíticas puede determinar la distribución de $\operatorname{ROS}^{25}$. En los valores obtenidos se observó un incremento de la actividad SOD en la etapa de madurez, cuando los niveles de $\mathrm{P}_{4}$ son máximos, lo cual cumple la función de proteger localmente contra el aumento de los RL producidos en esta etapa.

Se afirma que las actividades de SOD y catalasa se incrementan 6-8 veces desde el día 6 al 16 del ciclo estral y luego descienden durante la regresión luteal; así la catalasa disminuye cerca del $40 \%$ y la SOD alrededor del $60 \%$. Ha sido demostrado que el superóxido producido en el sistema xantina-oxidasa inhibe la síntesis de $\mathrm{P}_{4}$ en células luteales de rata y produce daños en las células luteales, inhibiendo proteínas de membrana y aumentando la fluidez de la membrana. Los niveles altos de catalasa y SOD al día 16, donde la síntesis de progesterona es máxima, probablemente tengan la función de proteger localmente contra los RL producidos ${ }^{19}$. La correlación de la esteroidogénesis con los niveles de las enzimas estudiadas en esta investigación, indica que los mecanismos antioxidativos son activados por el estrés oxidativo asociado a la síntesis de hormonas esteroideas, en coincidencia con lo reportado por otros autores ${ }^{19}$.

\section{b. Identificación de $\mathrm{Cu}-\mathrm{Zn}-\mathrm{SOD}$}

En todos los cortes histológicos de CL maduros sometidos a la técnica de inmunofluorescencia indirecta (IFI) se observaron abundantes gránulos fluorescentes homogéneos, de variado tamaño, distribuidos de forma multifocal e intracitoplasmáticos, tanto en células luteales grandes como pequeñas, todas ellas diferenciadas del tejido de fondo no fluorescente, lo que confirió mayor contraste al preparado. Estos resultados corroboraron que la enzima CuZn-SOD se ubica en el citoplasma de las células del CL maduro.

Al comparar cualitativamente la cuantía de gránulos fluorescentes, se constató que 57 CL maduros $(71,25 \%)$

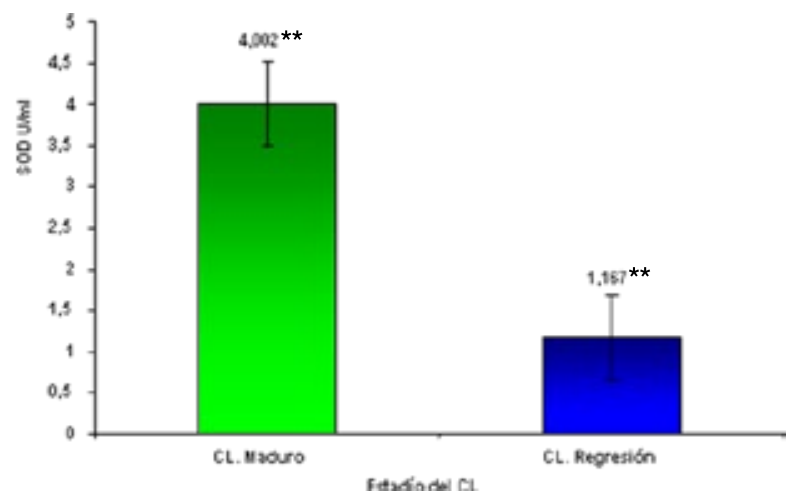

Figura 1. Niveles de SOD en cuerpos lúteos bovinos $(n=31)$. Valores en $X \pm D E,{ }^{* *} p<0,05$. presentaron alto contenido, 22 de ellos $(27,5 \%)$ mostraron moderado contenido y sólo un CL $(1,25 \%)$ reveló contenido escaso. Por su parte, al observar bajo el microscopio de fluorescencia los cortes histológicos del total de CL en regresión, se evidenció escasa cantidad de pequeños gránulos verdes fluorescentes homogéneos contenidos en el citoplasma de las células luteales y distribuidos multifocalmente. El tejido de fondo tampoco presentó fluorescencia, lo que indicó la expresión de la enzima $\mathrm{Cu}-\mathrm{ZnSOD}$ en el citoplasma de las células del cuerpo lúteo en regresión.

Cuando se comparó cualitativamente la presencia en mayor o menor grado de los gránulos de fluorescencia se obtuvo que $38 \mathrm{CL}$ en regresión (71,69\%) presentaron un leve contenido de gránulos fluorescentes, mientras que los restantes $15 \mathrm{CL}(28,3 \%)$ presentaron moderado contenido de gránulos fluorescentes (Figura 2).

Cualitativamente pudo evidenciarse una mayor expresión de la enzima CuZn-SOD en los CL maduros que en los regresivos. Además, existió asociación significativa con una correlación del $33 \%(\mathrm{p} \leq 0,05)$ entre los dos estadios de CL y la presencia de gránulos de inmunofluorescencia en el citoplasma de las células luteales (Figuras 3, 4, 5 y 6).

Estos resultados concuerdan con los obtenido por autores que reportan que en bovinos el CL maduro expresa significativamente mayores niveles de $\mathrm{CuZn}-$ SOD y Mn-SOD al compararlo con el CL en regresión, por lo cual concluyen que durante la luteólisis ocurre una disminución en la expresión de genes específicos encargados de la respuesta oxidativa ${ }^{3,7,20}$, y que mantener la expresión de esos genes en el CL durante la preñez puede prevenir el daño oxidativo y retrasar la regresión, etapa en la cual el balance de la actividad de las enzimas luteolíticas puede determinar la distribución de las ROS ${ }^{25}$. Nuestros hallazgos también se asemejan a otros anteriormente reportados, indicando que la actividad SOD presenta un aumento creciente desde la fase inicial a la media en el CL humano y disminuye en forma gradual, por lo cual los valores más bajos se presentan en la fase de regresión ${ }^{21,23}$.

Un aumento en dicha actividad enzimática durante la gestación temprana fue evidenciada por autores

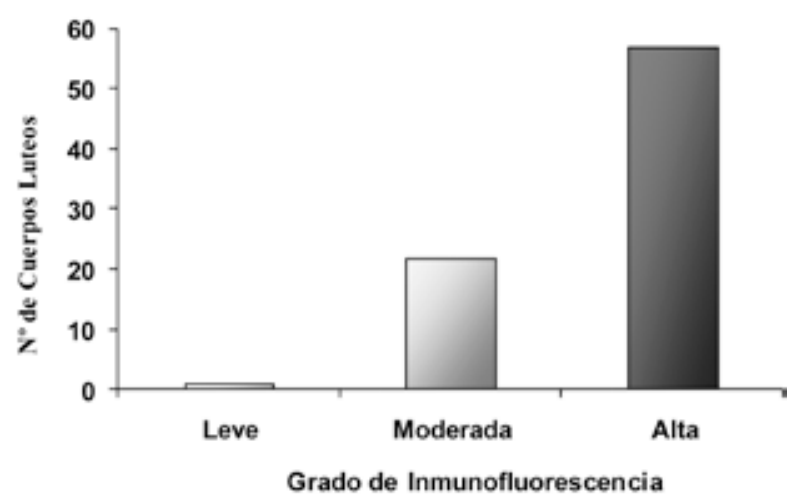

Figura 2. Grado de IFI en cuerpos lúteos maduros $(n=31)$. Valores en $X \pm D E$. 
que aseveran que la gonadotropina coriónica humana (HCG) puede ser importante para mantener la integridad de la célula luteal cuando ocurre la gestación ${ }^{22}$. Anteriormente otros investigadores habían reportado que la prolactina y los lactógenos placentarios estimulaban la expresión de SOD en ratas, fenómeno importante para mantener la capacidad esteroidogénica de dichas células ${ }^{21}$.

El estrés oxidativo provocado por la disminución de vitamina $\mathrm{E}$ antes del parto, ha sido relacionada con la aparición de retención placentaria, por acción de los lipoperóxidos o retrasos en la aparición del primer celo ${ }^{6}$. Se ha señalado que las hembras bovinas que presentan una mayor generación de ROS en células luteales mostrarán peroxidación lipídica, afectando a sus membranas, con importantes consecuencias como pérdida de receptores para gonadotrofinas, disminución de la formación de adenosin-monofosfato cíclico o de la capacidad esteroidogénica del CL durante la involución.

Existe una alta correlación entre el aumento de la actividad SOD en los CL bovinos maduros y la presencia de la enzima por IFI en los CL en la misma etapa, lo cual demuestra que durante esta fase hay una alta

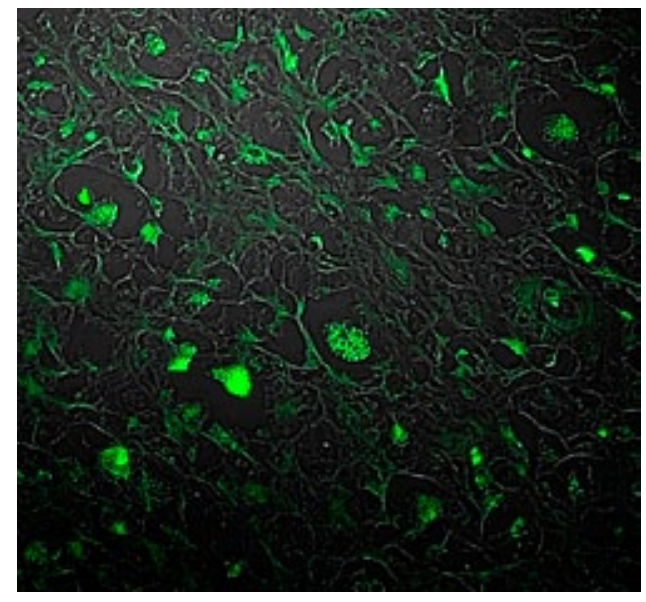

Figura 3. Cuerpo lúteo maduro. IFI. Microscopio confocal, $20 \mathrm{X}$.

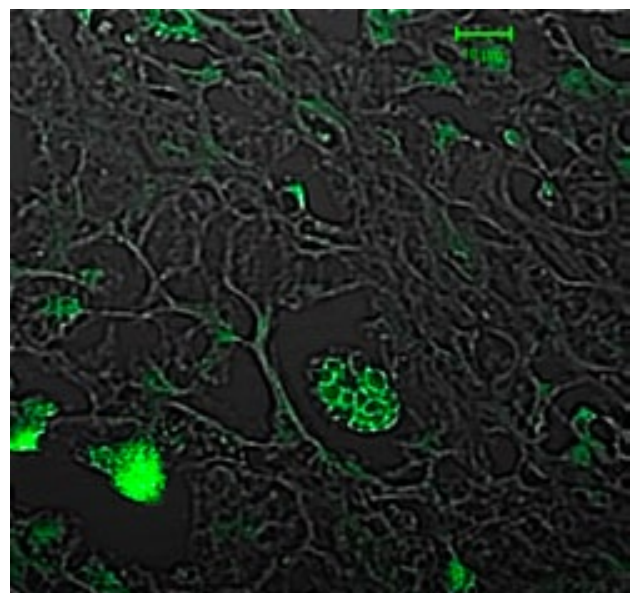

Figura 4. Cuerpo lúteo maduro. IFI. Microscopio confocal, $40 \mathrm{X}$, expresión de la enzima, posiblemente como resultado del aumento de la síntesis de $\mathrm{P}_{4}$, lo que representaría un importante mecanismo de defensa celular, porque en la fase de madurez del CL se determinó que el proceso de peroxidación lipídica luteal está aumentado ${ }^{15}$. Por esta razón la actividad de la enzima se encuentra en niveles máximos, confirmando el reporte de otros autores quienes indican que la actividad SOD en el CL de ratas preñadas y conejas pseudopreñadas, es también paralela a la concentración de progesterona del plasma ${ }^{12,13}$, lo que indicaría que la actividad SOD es corregulada con la esteroidogénesis del CL de animales con diferentes perfiles del ciclo estral ${ }^{19}$.

Sin embargo, anteriormente fue evidenciado un aumento progresivo en las actividades CuZn-SOD y GPx durante las diferentes etapas (inicial, media y final) del CL en ovejas, con un mayor aumento en la fase final, además de un aumento en la actividad de Mn-SOD y glutation S-transferasa, hallazgos que permiten inferir que la capacidad antioxidante no está correlacionada con el estado esteroidogénico de las células ${ }^{1}$, resultado

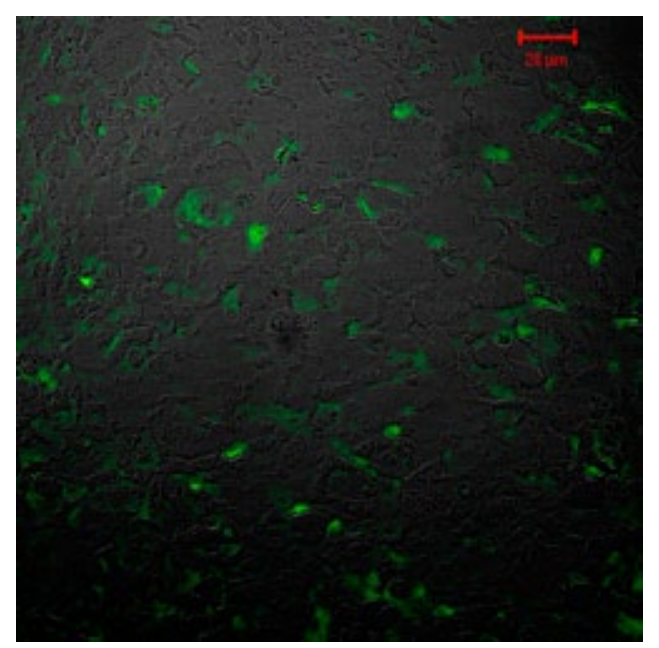

Figura 5. Cuerpo lúteo en regresión. IFI. Microscopio confocal, $10 \mathrm{X}$.

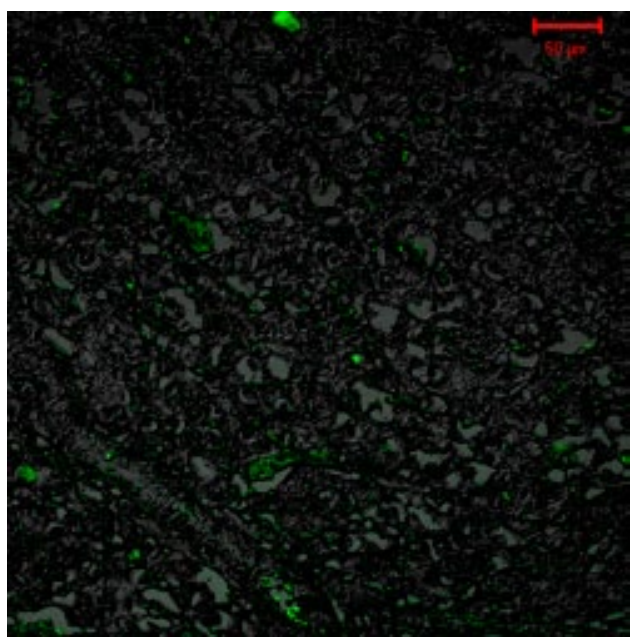

Figura 6. Cuerpo lúteo en regresión. IFI. Microscopio confocal, $20 \mathrm{X}$. 
que difiere al encontrado en la presente investigación. Los mismos investigadores demostraron un aumento en la actividad de enzimas antioxidantes durante los primeros 40 días de gestación en ovejas, e indicaron que este aumento puede estar ligado a las ROS generadas continuamente en las células luteales esteroidogénicamente activas y estaría implícito en el mantenimiento de la actividad esteroidogénica luteal y la integridad celular durante la gestación temprana ${ }^{2}$.

Al valorar la actividad de las enzimas CuZn-SOD, Mn-SOD, catalasa, GPx y glutation reductasa a las 0 , 12, 24 y 48 horas después de la inyección de $\mathrm{PGF}_{2} \alpha$ durante el día 10 del ciclo estral de ovejas, se evidenció que esta hormona induce muerte de las células luteales sin alterar la actividad de dichas enzimas antioxidantes, sólo la catalasa aumentó a las 12 y 24 horas después del tratamiento, sugiriéndose que ese aumento transitorio es una respuesta de adaptación del CL al proceso oxidativo causado por la $\mathrm{PGF}_{2} \alpha^{8}$. Sin embargo, los efectos de esta hormona en el sistema de SOD y GPx del CL no han sido aclarados todavía, aunque la regresión luteal es causada parcialmente por el incremento de las ROS ${ }^{11}$.

Las ROS estimulan la producción de $\mathrm{PGF}_{2} \alpha$ en células del endometrio humano y éstas pueden afectar la función endometrial al regular la producción de dicha hormona ${ }^{22}$. Al respecto, en CL en regresión de ratones (comparado con CL funcionales), se observó un aumento de la ciclo-oxigenasa-2, enzima limitante de la síntesis de prostaglandinas, así como aumento de la peroxidación lipídica y de la actividad SOD total, además de una disminución en la actividad de la catalasa ${ }^{9}$.

Para los diferentes mecanismos capaces de aumentar la expresión de SOD, algunos investigadores reportan un incremento in vitro de la expresión de esta enzima en células endometriales humanas inducida por estrógenos y progesterona, además indican que en el caso de la Mn-SOD este aumento ocurre por vía del $\mathrm{AMPc}^{22}$.

En base a estos resultados se puede concluir que existe producción de radicales libres y actividad SOD, así como presencia de la enzima en el CL maduro al compararlo con el CL regresivo. Ello puede deberse a la alta capacidad esteroidogénica de este órgano durante el estadio de madurez, el cual merced a su gran poder antioxidante no padece estrés oxidativo, asegurando el cumplimiento de la vida media del CL funcional.

Agradecimientos. Al CDCHT de la UCLA por el financiamiento para realizar este trabajo. A la Asociación El Tunal por facilitar los animales.

\section{REFERENCIAS}

1. Al-Gubory K, Bolifraud P, Germain G, Nicole A, Ceballos I. 2004. Antioxidant enzymatic defense system in sheep corpus luteum throughout pregnancy. Reprod Res 128: 767-777.

2. Al-Gubory K, Ceballos I, Nicole A, Bolifraud P, Germain G, Michaud M, Mayeur C, Blachier F. 2005.
Changes in activities of superoxide dismutase, nitric oxide synthase, glutathione-dependent enzymes and the incidence of apoptosis in sheep corpus luteum during the estrous cycle. Biochim Biophys Acta 10: 348-357.

3. Behrman H, Aten R. 1991. Evidence that hydrogen peroxide blocks hormone sensitive cholesterol transport into mitochondria of rat luteal cells. Endocrinology 128: 2958 2966.

4. Bendich A. 1993. Physiological role of antioxidants in the immune system. J Dairy Sci 76: 2789-2794.

5. Carlson J, Wu X, Sawada M. 1993. Oxygen radicals and the control of ovarian corpus luteum function. Free Radic Biol Med 14: 79-84.

6. Castillo C, Benedito J, López M, Miranda M, Hernández J. 2001. Importancia del estrés oxidativo en ganado vacuno en relación con el estado fisiológico (preñez y parto) y la nutrición. Arch Med Vet 33: 7-15.

7. Fuentes M. 2001. Enzimas antioxidantes y su correlación en cuerpo lúteo bovino. Trabajo final, Posgrado de Producción de Leche. Biblioteca Facultad de Ciencias Veterinarias, UCLA, Barquisimeto (Venezuela), 44 p.

8. Garrel C, Ceballos I, Germain G, Al-Gubory K. 2007. Oxidative stress-inducible antioxidant adaptive response during prostaglandin F2 alpha-induced luteal cell death in vivo. Free Radic Res 41: 251-259.

9. Greenhalgh E. 1990. Luteal steroidogenesis and regression in the rat: effect of human gonadotrophin and phospholipase A2 on cell and plasma membranes. J Endocrinol 125: 387-396.

10. Gür S, Türk G, Demirci E, Yüce A, Sönmez M, Ozer S, Aksu EH. 2010. Effect of pregnancy and foetal number on diameter of corpus luteum, maternal progesterone concentration and oxidant/antioxidant balance in ewes. Reprod Domest Anim 46: 289-295.

11. Halliwell B, Gutterridge J. 1989. Free radicals in biology and medicine, $2^{\circ}$ ed., Clarendon Press, Oxford, p. 4-57.

12. Hesla J, Miyazaki T, Dsko L, Wallach E, Dharmarajan A. 1992. Superoxide dismutase activity, lipid peroxide production and corpus luteum steroidogenesis during natural luteolysis and regression induced by oestradiol deprivation of the ovary in pseudopregnant rabbits. $J$ Reprod Fertil 95: 915-924.

13. Laloraya M, Pradeep KG, Laloraya MM. 1988. Changes in the levels of superoxide anion radical and superoxide dismutase during the estrous cycle of Rattus norvegicus and induction of superoxide dismutae in rat ovary by lutropin. Biochem Biophys Res Commun 157: 146-153.

14. Lamirande E, Gagnon C. 1994. Reactive oxygen species and reproduction. In: Free radicals in diagnostic medicine (Armstrong D ed.), Plenum Press, New York, 936 p.

15. Márquez Y. 2001. Determinación de los parámetros de peroxidación lipídica en células luteales de hembras bovinas lecheras. Trabajo de ascenso, Facultad de Ciencias Veterinarias, UCLA (Barquisimeto, Venezuela), $57 \mathrm{p}$.

16. Ohkawa H, Ohihi N, Yagi K. 1978. Assay for lipid peroxides in animal tissues by thiobarbituric acid reaction. Anal Biochem 95: 351-358.

17. Oliveira A. 2009. Vías implicadas en la luteólisis. Rev Colom Cs Pec 20: 133-143. 
18. Pryor WA, Castle L. 1984. Chemical methods for the detection of lipid hydroperoxides. Methods Enzymol 105: 293-299.

19. Rapoport R, Sklan D, Wolfenson D, Shaham A, Hanukoglu I. 1998. Antioxidant capacity is correlated with steroidogenic status of the corpus luteum during the bovine estrous cycle. Biochim Biophys Acta 1380: 133-140.

20. Rueda B, Tilly K, Hansen T, Hoyer P, Tilly J. 1995 Expression of superoxide dismutase, catalase and glutathione peroxidase in the bovine corpus luteum: evidence supporting a role for oxidative stress in luteolysis. Endocrine 3: 227-232.

21. Sugino N, Hirosawa M, Zhong L, Telleria C, Shiota K, Gibori G. 1998. Hormonal regulation of copper-zinc-superoxide dismutase and manganese superoxide dismutase messenger ribonucleic acid in the rat corpus luteum, induction by prolactin and placental lactogenus. Biol Reprod 59: 599-605
22. Sugino N, Takiguchi S, Kashida S, Karube A, Nakamura Y, Kato H. 2000. Superoxide dismutase expression in the human corpus luteum during the menstrual cycle and in early pregnancy. Molec Hum Reproduct 6: 19-25.

23. Vega M, Castillo T, Retamales I, Heras J, Dovotto L, Videla L. 1994. Steroidogenic capacity and oxidative stress-related parameters in human luteal cell regression. Free Radic Biol Med 17: 493-499.

24. Wallin B, Rosengren R, Howard G, Shertzer G, Camejo G. 1993. Lipoprotein oxidation and measurement of thiobarbituric acid reacting substances formation in a single microtiter plate: its use for evaluation of antioxidants. Anal Biochem 208: 10-15.

25. Wu X, Sawada M, Carlson J. 1992. Stimulation of phospholipase $\mathrm{A}_{2}$ by xanthine oxidase in the rat corpus luteum. Biol Reprod 47: 1053-1058.

\section{Asociación Cooperadora de la Facultad de Ciencias Veterinarias}

Personería Jurídica No 647/92 y 912/00

Sargento Cabral 2139

3400 Corrientes

La Asociación Cooperadora de la Facultad de Ciencias Veterinarias fue constituida el 10 de diciembre del año 1991 como entidad de bien público, con el objeto de promover y coadyuvar las actividades científicas, educativas y culturales relacionadas con las Ciencias Veterinarias. En tal sentido, implementa acciones para colaborar con la enseñanza, extensión, actualización y difusión científica que realiza dicha Casa de Estudios.

Beneficios que brinda a sus asociados:

- Fotocopias con descuentos especiales del $20 \%$ en la Fotocopiadora COPIAS.COM que funciona dentro del predio de la Facultad de Ciencias Veterinarias.

- $10 \%$ de descuento para la adquisición de libros de la Editorial Inter-Médica.

- $10 \%$ de descuento en las compras de medicamentos e insumos para trabajos prácticos hospitalarios. 